\title{
ECONOMY IN GOVERNMENT CONTRACTING- ATOMIC ENERGY COMMISSION EXPERIENCE
}

\author{
JAMES T. RAMEY*
}

President Johnson has pledged that the executive branch "will be administered with the utmost thrift and frugality; that the Government will get a dollar's value for a dollar spent; and that the Government will set an example of prudence and economy."

Heads of departments and agencies, responding to this pledge, are undertaking affirmative action to carry out this request-including the initiation of cost reduction programs, the de-emphasis of cost-type contracting, and the re-emphasis of fixed-price and incentive-type contracting. Accordingly, there is occasion to examine carefully the experience of the Atomic Energy Commission (AEC) with regard to economy in contracting, and particularly in regard to the use of various forms and methods of contracting.

In evaluating various forms and methods of contracting, there must be considered the whole "system" of contracting used by the agency and indeed the organization and functions of the agency as a whole. What is desirable for one type of system may not work well for another; similarly, one form of contract may work well for one type of function or operation but may not work very well for another.

In very broad terms, the AEC is responsible for a program of manufacturing fissionable material and atomic weapons; developing nuclear propulsion systems for naval vessels; conducting research and development aimed at improved weapons, more efficient production, generation of useful power from atomic energy, utilization of radioactive material for medical, biological, and health purposes; and regulating the peaceful uses of atomic energy. Thirteen Field Offices carry out the atomic energy program under the general direction and supervision of the AEC Headquarters office.

Most AEC work is accomplished by contractors. There are more than 135,000 persons working directly in the program, of which approximately 7,000 are AEC employees. The rest work for our contractors. At present, the AEC investment in plant, equipment, and real estate is approximately eight billion dollars, and operating costs are at an annual level of approximately $\$ 2.7$ billion. These government-owned facilities are managed and operated for the AEC by contractors. Our operating contractors comprise a variety of industrial, academic, and not-for-profit organiza-

- Commisioner, Atomic Energy Commission.

The author wishes to acknowledge the contributions and assistance of the following members of the Commission staff: John V. Vinciguerra, Director, Division of Contracts; James Scammahorn, Assistant Director, Division of Contracts; and James P. Murray, Jr., Attorney, Office of the General Counsel.

${ }^{1}$ Address of President Johnson to Joint Session of Congress, Nov. 27, 1963, H.R. Doc. No. 178, 88th Cong., Ist Sess. 3 (1963). 
tions. Thus, for example, our Savannah River plutonium production plant down at Augusta, Georgia, is operated by DuPont. Oak Ridge is operated by Carbide. Our two weapons laboratories at Los Alamos, New Mexico and Livermore, California are, interestingly enough, operated by the University of California, and so on. Clearly the core of the AEC method of operation is by means of contracts.

The atomic energy enterprise is largely owned by the people of the United States, and its operation is directed toward the paramount objective of assuring the common defense and security and, beyond that, toward obtaining for the people the many constructive benefits that atomic energy offers. Congress intended that the Commission continue the Manhattan Engineer District's practice of contracting with industrial concerns and academic institutions to perform the actual operations of AEC-owned plants and laboratories. Under the terms of the Atomic Energy Act, this course is explicitly permitted. The unanimous report of the Senate Special Committee on Atomic Energy that drafted the original act stated: ${ }^{2}$

Wherever possible, the committee endeavors to reconcile Government monopoly of the production of fissionable material with our traditional free enterprise system. Thus, the bill permits management contracts for the operation of Government-owned plants so as to gain the full advantage of the skill and experience of American industry.

While the operation of AEC plants and laboratories comprises the core of our contracting program, the Commission's overall contracting activities include a large number of contracts and subcontracts for research and development and testing in private industrial and university facilities. AEC also annually expends two to three hundred million for construction and modification of facilities which are handled by various types of construction contracts and subcontracts.

\section{Use of the Administrative or Management Contract}

To carry out its responsibilities for the operations of its plants and laboratories, the AEC adopted the "administrative" or "management" contract," which in part was a carry-over of a contracting concept from the Manhattan Engineer District of World War II days. This form of contracting represented the development of a working relationship between government and industry. While it had been used in various situations, as far as I know it was not previously used extensively in government contracting programs with industry.

Under this contracting concept, the government-industry/university relationship is sometimes characterized as a partnership or cooperative arrangement." In short, under the "administrative" or "management" contract, the AEC is responsible for "what" is to be done and the contractor for "how." That is, the AEC retains the responsibility for overall program management and direction including the develop-

ISenate Special Committee on Atomic Energy, S. ReP. No. I2II, 79th Cong., 2d Sess. I5 (1946).

The administrative contract is discussed in Ramey \& Erlewine, Introduction to the Concept of the "Administrative Contract" in Government Sponsored Research and Development, I7 FED. B.J. 354 (I957).

4Richard A. Tybout, Government Contracting in Atomic Energy 88-89, 175-78 (1956); Morgan Thomas, Atomic Energy and Congress 9 (1959). 
ment or approval of long range program plans; establishment of basic policies and program objectives; budget and cost ceilings; and audit and evaluation of program execution and performance. On the other hand, the contractor is responsible for the day-to-day management to carry out the work.

The AEC "administrative" or "management" contract is cost-type and includes provisions giving the government the right to exercise appropriate control over the work consistent with the "partnership" nature of the arrangement.

In line with this relationship there are several contract provisions which specifically reserve to the government the right to control the work and to assure a judicious expenditure of government funds. For example:

I. Provisions for AEC to approve program objectives.

2. Approval of subcontract actions-generally over \$ro,000.

3. Approval of salaries over $\$ 25,000$ and assurance that other wage and salary and employee benefits are reasonable and consistent with commercial practices.

4. Establishment of procurement, financial and accounting systems consistent with government requirements.

The degree of actual supervision or control over the contractor will vary with the experience and capability of the contractors. The contract is so designed to provide for this kind of flexibility. AEC is organized under a decentralized contract administration system. The field offices, which are located at the site of the work, are generally organized to provide counterparts to the operating contractor's managerial, technical and administrative staff. Both AEC and contractor staffs, as a result of the continuity peculiar to AEC's programs, have accumulated above normal experience and training.

AEC personnel are in a position to maintain close liaison with contractor personnel having operational and other management responsibilities for the company and to exercise such supervision and control over the manner and methods of operation as may be necessary or desirable to insure that program objectives and schedules established by AEC are met and that expenditures made by the contractor from public funds are made in accordance with the provisions of the contract which reflect applicable legal and AEC policy requirements. These AEC staff functions include examination and evaluation of managerial actions, operations and nonroutine maintenance functions; frequent observations of the activities being conducted in the plants and facilities; and daily contact with the contractor personnel on operational and management problems generally.

In addition to the routine conferences for resolving the many day-to-day operating problems, AEC also has a program of formal review and evaluation of contractors. Under the program, AEC appraises the adequacy of the contractor's management activities; cost of services rendered; achievement of program objectives; and compliance with applicable laws, regulations and AEC instructions. Any question- 
able conditions or practices are brought to the attention of the contractors' management and appropriate remedial action is taken.

Although there are many similarities between the usual cost-plus-fixed-fee (CPFF) contract and AEC's administrative or management contracts, there are some fundamental differences. AEC's CPFF operating contracts are not conceived of as involving a seller and a buyer and a specialized method of arriving at a price for the thing sold or service provided. On the contrary, our operating contracts seek to establish long-term working relationships more akin to those between a board of directors and a manager, or between a home office and a branch office. These contracts, in the nuclear materials and weapons production sphere, are conceived of as management arrangements rather than contracts for product. Similarly, our contracts for the operation of laboratory facilities are not viewed as contracts for research so much as contracts for the management of research facilities. So conceived, the contracts are drawn and administered in a fashion designed to promote a close, cooperative relationship between the parties. This relationship facilitates the responsiveness of individual contractors to changes in the direction, scope, and intensity of their efforts, which might be necessary in order better to fit the particular contractor's current activities into overall AEC programs.

The differences between traditional concepts of the CPFF contract and the AEC's operating contracts are emphasized because these differences provide the key to understanding why the Commission continues to believe that in the context of our own activities these arrangements are generally best suited to the successful accomplishment of the programs in which they are employed at the lowest possible cost.

A fundamental similarity among all CPFF contracts, including AEC's operating contracts, must be conceded, however. None of them offer a profit motivation for reducing costs.

Notwithstanding the lack of a profit motive to reduce costs, it has been AEC's experience to date that significant cost reductions can be "administered" into its operating contracts. The reasons for this are twofold: first, because AEC, in the main, has responsible and experienced contractors who have no incentive to raise costs, and are responsive to efforts to lower costs; and secondly, because of the unusual fashion in which AEC is set up to administer and exercise the rights of direction and control as provided in its administrative contracts.

It may be argued that no matter how skillfully and extensively a CPFF contract is administered, there is no real substitute for the profit motive. Conceding this point, arguendo, the CPFF contract provides a substantial incentive for high. quality performance for the very reason that the profit motivation to reduce costs is absent. By the same token, there is no incentive to cut corners on safety-a matter of the utmost significance to the AEC. These last two factors are regarded as amply. offsetting any theoretical difference in cost performance pursuant to a profit incentive, 


\section{Cost Reduction Programs Within AEC}

One of the more successful efforts to achieve cost reductions resulted from AEC's early efforts to stimulate competition between its contractors. Indicative of these early efforts is a report dated June 8, I953 from the Chairman of the AEC to the Joint Committee on Atomic Energy, which reads in part: ${ }^{5}$

In the past, competition within the program has been limited because the major activities were concentrated in single facilities where contractors had only their own past performance against which to compete. With the expansion programs of the past and forthcoming few years, new facilities are being constructed for production of U-235, plutonium and weapons. There will thus for the first time be an opportunity for healthy rivalry in plutonium production between such contractors as General Electric and duPont, and in production of $\mathrm{U}-235$ between Goodyear and Carbide. While there will be many disparate factors to be taken into account in comparing performance of these firms, the presence of rivals will, we are confident, do much to stimulate aggressive improvement of management.

Another key factor has been the AEC's cost accounting system. Since I953 AEC Field Offices have continuously used product cost data to measure and evaluate the progress of contractors engaged in production activities. In turn, this information has been used by contractors in determining cost trends and in evaluating their own efficiency. To assist contractors to better perform these functions, Field Offices have set up Production Cost Comparison Committees composed of AEC and contractor accounting and technical representatives. These committees have met periodically at different contractors' plants to study the production operations at first hand and to analyze and compare product costs and highlight less efficient operations. This effort has contributed to significant savings.

A knowledge of comparative costs for the same or similar products produced by two or more plants has enabled management to develop production schedules for such plants at the least cost to the AEC. Contractors have made extensive use of product cost data in the preparation of production budgets. Field Offices also use these data in evaluating the contractors' estimates. Both Field Office and Headquarters staff use product cost data as the basis for making decisions regarding revisions of the original budget estimates. At Headquarters, a knowledge of unit product costs has been an effective tool in the overall planning and scheduling of production requirements. Not surprisingly, the trend in unit cost of all principal AEC products has been downward throughout the past ten years.

As to be expected in the comparatively new and young nuclear industry, many of the reductions have resulted from technical improvements in production methods and processes. For example, the dramatic success achieved in process development and cascade improvement resulted in reduction of the wartime peak operating personnel strength at the Oak Ridge Gaseous Diffusion Plant from about II,000 to around 5,000 by 1958 . With further developments in instrumentation and control systems this number has been reduced to the present level of roughly 2,600. Other

\footnotetext{
s (Unpublished.)
} 
reductions have also been attributed to improved management-planning, scheduling, and utilization of available capacity-and to economies in costs of operations. The competition among contractors has been a most significant factor, even without the profit motive. The desire to perform better and at lower cost than one's competitor is seemingly a natural instinct.

Current AEC cost reduction efforts include development of specific guidelines for contractor cost reduction programs. The purposes of these guidelines are:

r. To encourage individual contractors to intensify their efforts in achieving cost reductions in the performance of government contracts.

2. To establish the minimum criteria for an effective government contractor cost reduction program as related to government business.

3. To provide for qualitative review by the government of the individual contractor cost reduction policies, systems, and procedures to make possible the application of the policies and criteria stated above.

A further step to give additional impetus to the program includes communications with selected AEC contractors requesting assistance in achieving significant further cost reductions and apprising them that field managers will call on them to discuss the importance of cost reduction actions and to establish a system of periodic reporting of pertinent actions taken. In $x 963$, estimated savings from cost reduction actions in AEC exceeded $\$ 95$ million, and this is expected to rise to over $\$ 150$ million in $x 964$.

\section{Cost-Plus-Fixed-Fee Contracts}

As a part of their cost reduction program, some agencies are strongly pushing the use of fixed-price and cost-plus-incentive-fee (CPIF) contracts in lieu of cost-plusfixed-fee (CPFF) contracts. For example, Department of Defense (DOD) representatives have stated that savings ${ }^{6}$ of twenty-five per cent and ten per cent respectively are effected by the use of such contracts instead of the use of CPFF contracts.

In considering the reduction of DOD's use of the CPFF contracting technique, it is important to keep in mind that DOD's principal contracting activities relate to the procurement of weapons systems and components and are more oriented to the buyer-seller relationship while AEC's contractors are engaged to manage our plants and laboratories. The continuity maintained by AEC programs further facilitates the conception of AEC's operating contractor arrangement as not so much a specialized method for arriving at the price for a product sold or a service provided. Rather, these administrative or management contracts are drawn and administered in a fashion designed to promote a close cooperative relationship between the parties.

In summary, AEC's present position is that its operating contracts provide the best means for accomplishing the programs for which they are used at the least

\footnotetext{
- Hearings Before the Subcommittee on Defense Procurement of the Joint Economic.Committee, 88th Cong., Ist Sess. 29,36 (1963).
} 
cost, but this position does not rest entirely on their peculiar suitability for these programs. In part this view continues to be held because AEC takes a somewhat less enthusiastic view of the advantages of the available alternative contracting techniques than does the Department of Defense or the National Aeronautics and Space Administration (NASA).

Possible alternatives to AEC's CPFF operating contracts are some form of fixed price or unit price arrangement, with or without features such as escalation provisions or price redetermination provisions, or the CPIF contract. The potential fluctuations in production goals (for special nuclear material and weapons) seem clearly to eliminate the fixed or unit price contract. After much study AEC concluded that with such features as price redetermination, they are not suitable for the operation of production facilities-without reaching other possible problems with this type of contract for this purpose. So far as AEC's laboratory operations are concerned, there is little if any activity reasonably susceptible of fixed pricing. What is left as a practical matter is the incentive fee contract.

\section{Incentrive Contracting}

The incentive fee contracting technique is ingeniously attractive. It is a cost-type contract; but, instead of a fixed fee, the contract is set up so that the amount of fee will vary depending upon the contractor's performance as measured against a preestablished goal or "target." Targets are established for cost performance or technical performance or delivery performance, or combinations of the three, depending upon the particular contractual circumstances.

Assuming a simple case where the fee fluctuated only with cost performance, there would be a profit incentive to reduce costs and at the same time the protections against windfall profits and losses afforded by the CPFF contract would seem to be present. The term "seem to be present" seems appropriate because the effectiveness of the entire scheme hinges on the degree of certainty attaching to the cost target. The greater the accuracy with which the target can be established, the better the arrangement works.

However-and here is the rub-if the target can be established with a degree of accuracy that avoids windfall profits and losses, the question arises: Why cannot a fixed or unit price arrangement be employed rather than a cost-type arrangement?

While the writer does not know the answer to that question, he suspects that it lies in the proposition that a cost estimate can be of such a degree of certainty as to warrant establishment of a target for CPIF purposes while at the same time not being certain enough for fixed price purposes. How many cases fall in this category? From the use of this contracting technique by the DOD and NASA, they probably encounter quite a few. Although the Commission is looking for them, not many have been yet encountered in the AEC.

Application of the CPIF contracting technique to AEC's operating production contract situations has been examined carefully. The fact that the plants are wholly 
government-owned introduces significant complications into an already complex arrangement. For example, with the facilities being owned by AEC a most careful check would have to be maintained to assure that underruns of cost targets were not achieved by skimping on plant maintenance.

Despite a number of potential problems, the potential advantages of appropriate use of the CPIF technique in AEC operations are such that we are trying one out. The present contract with General Electric for the operation of the AEC's production plant at Pinellas Peninsula, St. Petersburg, Florida is the contract involved. Under this arrangement, the contractor's fee is increased or decreased within prescribed limits, as certain costs exceed or are less than the target costs estimated and agreed to by the AEC and the contractor. While it is too early to evaluate the results of the arrangement, $A E C$ officials directly associated with the project are enthusiastic about the results indicated to date.

Additionally, as something of an experiment, AEC entered into a research and development incentive arrangement with Aerojet-General Corp., Azusa, California, and Westinghouse Electric Corporation, Large, Pennsylvania, its subcontractor for the NERVA nuclear rocket project. In this case, the nature of the research and development effort did not lend itself to a conventional incentive approach of increase or decrease in fee based on specific goals for performance, time for completion, or cost; and the incentive fee is based on a broad base of performance reports and overall performance evaluation. The actual fee paid, within prescribed limits, is based on a unilateral determination by the government as to the contractor's performance. No reportable results are available at this time on this "incentive award" arrangement, although it does not appear to have wrought any miracles.

\section{Fixed-Price Contracting}

The question of fixed-price versus cost-type contracting in the numerous contracting situations outside of the context of the contracts for the operation of AECowned plants and laboratories has been of considerable concern to AEC. While it is firm AEC policy to use fixed-price contracts wherever possible, ${ }^{7} \mathrm{AEC}$ has had some unfortunate experiences where eagerness and enthusiasm for fixed-price contracting resulted in inappropriate use of these forms of contracts.

In one case, after award of a fixed-price contract covering pipe for one of our large reactor projects, it turned out that a cost-type contract would have been a more suitable arrangement because of the additional research and development which was necessary to get acceptable pipe. Even though there had been extensive pre-award inquiry of pipe manufacturers concerning .capacity and capability to produce the particular type pipe needed, it developed during the course of the work that the production process known to the trade had to be further developed and the necessary change orders could have been handled much easier and more appropriately under a cost-type contract.

${ }^{7}$ AEC Procurement Regulations $\S 9-3.404-3$ (a)(I), 4I C.F.R. $\$ 9-3.404-3$ (a) (I) (I962). 
In another instance AEC was faced with an inability to deliver acceptable components for a large accelerator at one of our laboratories. Notwithstanding that a contract for research and development covering the feasibility of building these key components had been made in advance of the award of the fixed-price contract covering production, problems arose concerning production methods and tolerances; and it developed that necessary changes and modifications to the contract required to accomplish the work could have been handled much better under a cost-type contract. In summary, AEC's most difficult problems with fixed-price contracting have developed in the procurement of items where some of the components were "first-of-their-kind," involving rigid specifications, close tolerances and high performance requirements.

Experiences such as this, plus a tendency to carry over to those more conventional contract situations the intensive administration applied to CPFF operating contracts, cause AEC to continue to feel that the CPFF contract, judiciously employed, can still play a vital role in selected situations in addition to the operating contractor situation.

Nevertheless, the writer strongly agrees on the general advantages of fixedprice contracting. AEC has had some very successful experiences, particularly in the procurement of cores for atomic propulsion of submarine and surface vessels in our Naval Reactor Program. As an example of the cost reductions that have been obtained in the Naval Reactor Program through competitive fixed-price contracting, AEC's experience in procurement of submarine reactor cores should be cited. These cores which can be considered as the heart of nuclear power plants are procured for the Navy by the AEC.

The price now paid for submarine cores is about one-third the amount AEC paid for the original cores we purchased. Although this significant reduction in price can be partially attributed to experience and to increased production, undoubtedly the method of contracting used-fixed-price competitive bidding-by providing core manufacturers with strong incentives to develop improved manufacturing processes and reduce production costs in other ways as well, played a significant part in the marked reduction in prices. Moreover, advances in core technology have at the same time increased the lifetime of naval reactor cores by a factor of three or more so that the cost of these cores per unit of energy produced has been reduced by about a factor of ten during a period of ten years.

The cost-type "management" contract, as utilized by the AEC for operation of its own production and research and development facilities, has proved to be a very useful tool. There are also a number of circumstances where the usual cost-type contract can be appropriately employed. We in AEC will continue to prefer the use of fixed-price contracts; but we will continue to guard against their improper use. 
SUMmary

The Atomic Energy Commission has devised an almost unique contracting technique to cover the operation of its government-owned plants and multi-program laboratories. This contracting technique, while nominally straight cost-type contracting, is in fact somewhat apart from the normal conception of a CPFF contract. The departure from the norm stems initially from the fact that the contractual arrangements are regarded as basically calling for the management of facilities rather than as being simply very complex ways of buying something.

The departure is augmented and implemented by specific contractual provisions providing broad rights of AEC control; and yet, in the interests of maximum operational flexibility, reserving exercise of this control to a tailor-made contract administration set-up. The combination of broad controls and extensive administration working in a carefully created atmosphere of cooperation serves to offset, to a degree not normally present in CPFF arrangements, the criticism that no profit incentive for cost reduction is present. Substantial alternative means for cost reductions are present, have produced positive results, and, under the spur of current all-out cost reduction programs, are continuing to do so. Moreover, the AEC's operating contracts, in emphasizing technical excellence and safety to an above-normal extent, appear better suited to their particular applications than other contract forms. With particular reference to the use of the incentive contracting method, the current view of the AEC is a cautious approach stemming from a more conservative regard for the benefits of this contracting method than seems to be held by DOD and NASA. Similarly, AEC continues to believe that, properly used, the CPFF contracting technique has a significant role also in conventional (i.e., non-operating) contract situations. 